\title{
Synthesis and biological activity of 4-amino-3-chloro-1H-pyrrole-2,5-diones
}

\author{
Halyna M. Kuznietsova ${ }^{1}$ (I) - Vasyl V. Hurmach ${ }^{1} \cdot$ Andriy V. Bychko $^{2}$ - Olena I. Tykhoniuk ${ }^{1} \cdot$ Demyd S. Milokhov $^{1}$. \\ Olga V. Khilya ${ }^{1} \cdot$ Yulian M. Volovenko ${ }^{1}$ - Volodymyr K. Rybalchenko ${ }^{1}$
}

Received: 26 November 2018 / Accepted: 4 April 2019 / Published online: 10 April 2019

(c) Springer-Verlag GmbH Germany, part of Springer Nature 2019

\begin{abstract}
4-Amino-3-chloro-1H-pyrrole-2,5-dione derivatives were designed and synthesized as potential tyrosine kinase inhibitors. One of them has been shown to inhibit growth of cancer cell lines and in vivo tumors. To determine the impact of side groups on biological activity the ability of different 4-amino-3-chloro- $1 \mathrm{H}$-pyrrole-2,5-diones to interact with ATP-binding domains of growth factor receptors and with model cell membranes were aimed to be discovered. The methods of molecular docking, short-molecular dynamics (in silico) and non-steady cyclic current-voltage characteristics (in vitro) were used. Five 4-amino3-chloro-1 $H$-pyrrole-2,5-diones were synthesized from 3,4-dichloro- $1 H$-pyrrole-2,5-diones. All of them demonstrated the potential ability to form complexes with ATP-binding domains of EGFR and VEGFR2. These complexes were more stable compared to those with ANP. 4-Amino-3-chloro-1H-pyrrole-2,5-diones while interact with different bilayer lipid membranes caused an increase of their specific conductance and electric capacity, demonstrating the certain disturbance in lipid packing. Obtained data allowed us to suggest that proposed chemicals can interact with the surface of lipid bilayer, do likely intercalate into the membrane and form stable complexes with EGFR and VEGFR2. So, the prospect of developed chemicals to be effective EGFR and VEGFR2 inhibitors and therefore realize antitumor activity was concluded.
\end{abstract}

Keywords 4-Amino-3-chloro-1H-pyrrole-2 · 5-Dione derivatives · EGFR · VEGFR2 - Bilayer lipid membranes · Cyclic current-voltage characteristics

\section{Introduction}

Malignant neoplasms as the cause of death occupy the second place in the overall mortality after the cardiovascular pathology. According to the World Health Organization, there are about 14 million new neoplasm cases registered in 2012, and 8.8 million cancer-related deaths in 2014 (Stewart and Wild 2014). Moreover, increase the number of new cancer cases up to $70 \%$ during the next 20 years is expected.

Along surgical rejection and radiotherapy chemotherapy is the most common method for neoplasm treatment. However, it has significant disadvantages. Traditional chemotherapeutic agents used today in medical practice act primarily

Halyna M. Kuznietsova

biophyz@gmail.com

1 Taras Shevchenko National University of Kyiv, 64/13 Volodymyrska St., Kiev 01601, Ukraine

2 Bogomolets National Medical University, 13, T. Shevchenko Blvd, Kiev 01601, Ukraine on proliferating cells. Therefore, they are low-specific for malignant cells and characterized by high frequency and severity of side effects. The last is one of the main factors which determines the proper chemotherapy and treatment outcomes (Di Maio et al. 2016). So the discovery of new agents which are highly specific to malignant cells could contribute to avoid (or at least reduce) the side effects and complications of the therapy and therefore is an important task for modern science and medicine.

The modern approach in neoplasms treatment is using the targeted therapeutics which may block hyperactivated through malignant degeneration signaling pathways including those associated with receptor and non-receptor protein kinases (Gerber 2008). Such agents possess high anti-tumor activity and significantly lower toxicity compared to common drugs. Representatives of those are monoclonal antibodies against protein kinases, e.g. growth factor receptors (EGFR, VEGFR, PDGFR), and low molecular synthetic multikinase inhibitors (Pestalozzi and Knuth 2004; Elez et al. 2008). Low molecular protein kinase inhibitors, as 
opposed to monoclonal antibodies, have a wider range of targets (Broekman et al. 2011), ability to penetrate into the cell, oral formulation and comparable cheap manufacturing (Gerber 2008). However, small number of such drugs is currently approved. Furthermore, they have the shortcomings like individual hypersensitivity, drug resistance due to mutations in the targeted receptor genes, and organ-specific toxicity (Kroschinsky et al. 2017). Taking into consideration the abovementioned, further discovery of synthetic multikinase inhibitors having the high therapeutic potential and low adverse effects remains relevant.

Maleimide derivatives are known as small-molecular protein kinase inhibitors, demonstrating high ability to inhibit different PKC isotypes and GSK-3 predominantly and to reveal cytostatic activity. Examples include bisindolylmaleimides (Pajak et al. 2008), arylindolylmaleimides (Liu et al. 2016), indolyl-naphthyl maleimides (van Eis et al. 2017). The panel of 1-(4-R-benzyl)-3-R1-4-(R2phenylamino)- $1 H$-pyrrole-2,5-diones were synthesized and tested on antiproliferative activity. Among them 3-chloro1-(4-chlorobenzyl)-4-((3-(trifluoromethyl)phenyl)amino)$1 H$-pyrrole-2,5-dione 2a (Table 1 ) demonstrated the ability to inhibit colon cancer cell lines HCT-116, SW-620, Colo$205\left(\mathrm{GI}_{50}\right.$ approximately $1.0-1.6 \times 10^{-8} \mathrm{M}$ ) (Dubinina et al. 2007; Garmanchuk et al. 2013a) and colonic tumors growth on rat chemically induced colon cancer model (Kuznietsova et al. 2013; Garmanchuk et al. 2013b), Furthermore, compound 2a reveals antioxidant properties (Kuznietsova et al. 2016) and low toxicity (Kuznietsova et al. 2015), so could be considered the promise basis for targeted antitumor drug development.

In our previous studies we demonstrated that biological activity of 4-amino-3-chloro- $1 H$-pyrrole-2,5-diones strongly depends on their side groups $\left(\mathrm{R}^{1}, \mathrm{R}^{2}\right.$ ) (Ostrovska et al. 2007). So we aimed to investigate the impact of side group slight modifications on biological activity of the substance.

Synthetic route to target compounds $\mathbf{2 a}-\mathbf{e}$ consists in treatment of 3,4-dichloro-1 $H$-pyrrole-2,5-diones 1a-d with the appropriate primary amine in ethanol (Scheme 1, Table 1).

Therefore, our purposes were (1) design and synthesis of few 4-amino-3-chloro- $1 H$-pyrrole-2,5-diones with insignificant differences of scaffold (Table 1), (2) testing

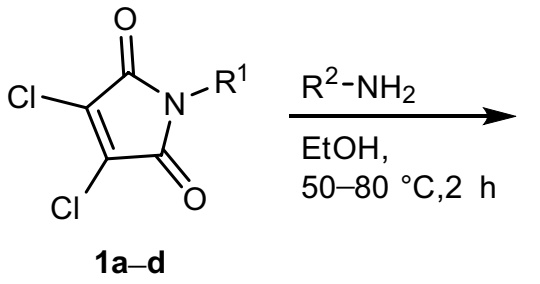<smiles>[R]NC1=C(Cl)C(=O)N([R])C1=O</smiles>

2a-e $84-93 \%$

Scheme 1 Synthetic route to target compounds $2 \mathbf{a}-\mathbf{e}$

Table 1 4-Amino-3-chloro-1H-pyrrole-2,5-diones 2a-e

\begin{tabular}{|c|c|c|c|c|}
\hline Compound & $\begin{array}{l}\text { Molecular } \quad \mathrm{R}^{1} \\
\text { formula }\end{array}$ & $\mathrm{R}^{2}$ & $\begin{array}{l}\text { Yield } \\
(\%)\end{array}$ & $\mathrm{Mp}\left({ }^{\circ} \mathrm{C}\right)$ \\
\hline $2 a$ & $\mathrm{C}_{18} \mathrm{H}_{11} \mathrm{Cl}_{2} \mathrm{~F}_{3} \mathrm{~N}_{2} \mathrm{O}_{2}$ & & 93 & $134-135$ \\
\hline $2 \mathbf{b}$ & $\mathrm{C}_{17} \mathrm{H}_{9} \mathrm{ClF}_{4} \mathrm{~N}_{2} \mathrm{O}_{2}$ & & 92 & $162-164$ \\
\hline $2 c$ & $\mathrm{C}_{17} \mathrm{H}_{9} \mathrm{Cl}_{2} \mathrm{~F}_{3} \mathrm{~N}_{2} \mathrm{O}_{2}$ & & 88 & $174-175$ \\
\hline 2d & $\mathrm{C}_{18} \mathrm{H}_{9} \mathrm{ClF}_{6} \mathrm{~N}_{2} \mathrm{O}_{2}$ & & 84 & $122-124$ \\
\hline $2 e$ & $\mathrm{C}_{18} \mathrm{H}_{13} \mathrm{Cl}_{3} \mathrm{~N}_{2} \mathrm{O}_{2}$ & & 86 & $117-118$ \\
\hline
\end{tabular}


their ability to interact with ATP-binding domains of growth factor receptors and to form the stable complexes, and (3) analysis of interaction between 4-amino-3-chloro$1 H$-pyrrole-2,5-diones and bilayer lipid membranes as surrounding matrix of targeted receptors. EGFR and VEGFR have been chosen for analysis because of their strong association with colon malignancies and using as targets of antitumor treatment.

\section{Materials and methods}

\section{Chemistry}

\section{General}

Melting points (Mp) were determined using a Kofler-type hotstage microscope (Boetius VEB Analytik) and are corrected. ${ }^{1} \mathrm{H}$ Nuclear magnetic resonance (NMR) and ${ }^{13} \mathrm{C}$ NMR spectra were recorded on a Varian Mercury-400 spectrometer at $400 \mathrm{MHz}$ and $100 \mathrm{MHz}$, respectively, in dimethyl sulfoxide (DMSO- $d_{6}$ ). Chemical shifts $(\delta)$ were given in ppm downfield from the internal standard tetramethylsilane (TMS). The $J$ values were given in $\mathrm{Hz}$. The infrared (IR) spectra were obtained on a Fourier transform infrared spectrometer Perkin Elmer BX II with $\mathrm{KBr}$ pellets. Elemental analyses were performed on a CHNOS elementar vario MICRO Cube analyzer and their results were found to be in good agreement $( \pm 0.3 \%)$ with the calculated values. The reaction progress was monitored by thin-layer chromatography (TLC) on Merck $60 \mathrm{~F}_{254}$ silica gel plates using hexanes-ethyl acetate (8:2) system as the eluent. 3,4-Dichloro-1 $H$-pyrrole-2,5-diones 1a-d were synthesized according to the procedure published in (Relles 1973).

\section{Procedure for the preparation of 4-amino-3-chloro-1 $\mathrm{H}$-pyrrole-2,5-diones (2a-e)}

To a solution of 3,4-dichloro- $1 H$-pyrrole-2,5-diones 1a-d $(10 \mathrm{mmol})$ in $50 \mathrm{~cm}^{3}$ of ethanol $20 \mathrm{mmol}$ of appropriate primary amine was added with stirring. The reaction mixture was heated at $50-80{ }^{\circ} \mathrm{C}$ temperature and stirred for $2 \mathrm{~h}$. Control of the reaction was carried by TLC monitoring. After completion of the reaction the solvent was evaporated in vacuo, product was filtered off, washed with ethanol and a small amount of ice water. The resulting product was purified by recrystallization from ethanol or column chromatography on silica gel (230-400 mesh) using hexanes-ethyl acetate $(7: 3)$ system as the eluent. The details for each compound are as follows (Table 2).

\section{In silico assays}

Molecular docking assays were performed using flexible ligand and rigid protein. We applied the algorithm of systematical docking (SDOCK+), built-in the QXP package (this method demonstrates all possible conformations of the studied structures with the minimal value of root mean square deviation (RMSD)) (Warren et al. 2006). We generated 300 potentially possible complexes of each compound (2a...2e) with epidermal growth factor receptor (EGFR) and vascular endothelial growth factor receptor (VEGFR). The 10 best of those were selected for the next stage, using a scoring function, built-in the QXP package (McMartin and Bohacek 1997). The interactions of 2a...2e compounds with proteins were characterized by the following parameters: (1) the number of hydrogen bonds, (2) the area of contacting surfaces of protein and corresponding structure, (3) the distance between the protein and docked structure, and (4) the total energy of the binding structure. The total energy of binding protein and related structure (FreE), the contact energy of interacting compounds $(\mathrm{Cntc})$, the energy of hydrogen interactions (Hbnd), the energy of steric clashes between protein and build-in structure (Bump) and the energy of steric clashes between the atoms of build-in structure (Int) were calculated. To assess the ability of tested compounds to compete with ATP in ATP-binding site of the protein we checked the same parameters for ANP-protein complex. ANP (phosphoaminophosphonic acid-adenylate ester) is the stable ATP analogue widely used for modeling the processes required ATP.

To assess the stability of obtained complexes, we conducted the short-molecular dynamics (MD, $500 \mathrm{ps)} \mathrm{using}$ a Nosé-Poincaré-Anderson algorithm (NPA) (Sturgeon and Laird 2000; Bond et al. 1999). The calculations were performed on the following parameters: temperature (in $\mathrm{K})$-300, pressure (in $\mathrm{kPa}$ ) - 100. We used TIP3P model of water (Jorgensen et al. 1983) with adding appropriate amount of $\mathrm{Na}+/ \mathrm{Cl}-$ ions to balance the energy of obtained complexes.

\section{Biological assays}

Bilayer lipid membranes (BLM) were constructed according to (Koper et al. 2006) by infliction of phosphatidylcholine (PC, Biopharm, Ukraine) or asolectin from soybean (AS, Sigma, USA) dissolved in n-decane (concentration was equal $23 \mathrm{mg} / \mathrm{ml}$ ) on the pore in Teflon partition (diameter $0.32 \mathrm{~mm}$ ) in $0.1 \mathrm{M} \mathrm{KCl}$ solution with $\mathrm{pH} 7.4$ and temperature $25-27{ }^{\circ} \mathrm{C}$. BLM formation was controlled by visual (microscope MBS-2, Russia) and potentiometric methods. Me used membranes which had electric capacity in the range of $0.3-1 \mu \mathrm{F} / \mathrm{cm}^{2}$. 


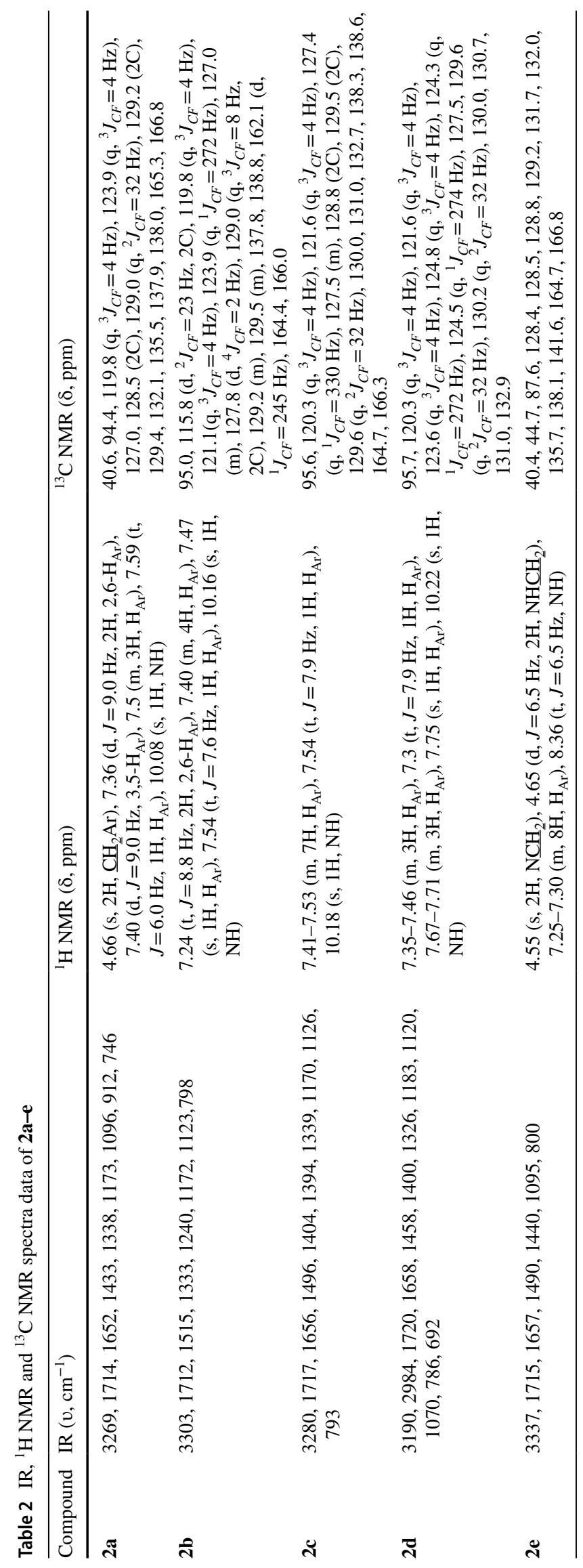


The effects of varying the concentrations of 4-amino-3chloro-1H-pyrrole-2,5-dione derivatives on BLM having various phospholipid compositions were investigated by non-steady cyclic current-voltage characteristics method (Arakelyan et al. 2014). The shift of potential on stimulating the $\mathrm{Ag}^{+} / \mathrm{AgCl}$-electrode located in outer compartment of the Mueller cell, was accomplished by applying alternating voltage $\pm 100 \mathrm{mV}(0.01 \mathrm{~Hz})$ having saw-edged shape. At the given frequency of the potential shift the most significant contribution to the net circuit resistance is given by its reactive (capacity) component, which is dependent on the circuit element having the greatest resistance (i.e. the hydrophobic region of BLM). The latter enables investigating the effect of the tested compounds on electric properties of BLM.

The obtained results were presented in the form of relative changes of specific conductance $(\mathrm{G})$ and electric capacity (C) of BLMs. Modification of BLMs by the tested compounds at different concentrations $\left(\mathrm{c} \times 10^{0}, \mathrm{c} \times 10^{-9}\right.$, $\mathrm{c} \times 10^{-8}, \mathrm{c} \times 10^{-7}, \mathrm{c} \times 10^{-6}$ and $\mathrm{c} \times 10^{-5} \mathrm{M}$ (where $\mathrm{c}$ is the initial concentration) was carried out by consecutive increment of the given concentration of the agent (with 10 min step). Determination of cyclic current-voltage characteristics was accomplished $10 \mathrm{~min}$ after the compound administration.

\section{Statistical assay}

All biological experiments were performed in triplicate and repeated 3 times. For statistical analysis of the obtained results, standard variation data within a group was calculated. Statistical reliability of differences between two groups of data was assessed by $T$ test. $\mathrm{p}<0.05$ was considered statistically significant.

\section{Results and discussion}

\section{In silico assays}

The energy parameters of complexes EGFR or VEGFR2 with 2a...e were lower compared with those with ANP. Thus, FreE, Cntc and Int values for ANP-EGFR complex were higher than those for 2a...e-EGFR: -6.0, -46.7 and $9.2 \mathrm{vs}-22.3-(-28.1),-59.5-(-64.2)$ and $3.3-7.6 \mathrm{~kJ} /$ mol, respectively. The similar situation was observed for VEGFR2 (Table 3).

We also checked the stability of modeled complexes. Thus, in ANP-EGFR complex RMSD for ANP was 1.49$3.41 \AA$ and for EGFR-0.51-1.81 $\AA$. In 2a...2e-EGFR complexes RMSD values were similar: $1.34-3.25 \AA$ for 2a...2e and 0.57-1.48 $\AA$ for EGFR. After MD there were no significant rearrangement in ANP-EGFR complex, as well as in 2a...2e-EGFR ones. Analyzing the stability of ANP-VEGFR2 and 2a...2e-VEGFR2 complexes we obtained resembling results: RMSD values for ANP and 2a...2e were $0.68-3.60 \AA$ and $0.49-2.6 \AA$ respectively, and for VEGFR2-0.52-1.62 ̊. Substantial rearrangements in analyzed complexes also weren't observed, confirming the stability of modeled complexes. Examples of MD results (for 2a-EGFR and 2a-VEGFR2 complexes) are depicted at Fig. 1.

Obtained data allowed us to suggest that proposed chemicals can form more stable complexes with EGFR and VEGFR2 compared to ANP, and therefore might successfully compete with ATP and its analogues for binding in ATP-binding sites of these receptors.
Table 3 The energy parameters (in $\mathrm{kJ} / \mathrm{mol}$ ) of complexes EGFR and VEGFR2 with 2a...e and ANP

\begin{tabular}{|c|c|c|c|c|c|c|}
\hline $\begin{array}{l}\text { The energy param- } \\
\text { eters, } \mathrm{kJ} / \mathrm{mol}\end{array}$ & ANP & $2 a$ & $2 b$ & $2 \mathrm{c}$ & $2 \mathrm{~d}$ & $2 \mathrm{e}$ \\
\hline \multicolumn{7}{|l|}{ EGFR } \\
\hline FreE & -6.0 & -28.1 & -25.8 & -22.8 & -22.3 & -24.5 \\
\hline Cntc & -46.7 & -61.3 & -59.9 & -59.5 & -64.2 & -60.8 \\
\hline Hbnd & -2.4 & -8.1 & -1.3 & -0.1 & -1.6 & -1.7 \\
\hline Bump & 3.3 & 5.5 & 7.5 & 6.2 & 6.4 & 6.1 \\
\hline Int & 9.2 & 7.6 & 3.3 & 4.1 & 4.3 & 6.7 \\
\hline \multicolumn{7}{|l|}{ VEGFR2 } \\
\hline FreE & -9.2 & -27.1 & -28.7 & -34.4 & -32.8 & -26.5 \\
\hline Cntc & -53.1 & -73.1 & -62.9 & -63.8 & -73.9 & -67.7 \\
\hline Hbnd & -2.6 & -2.0 & -1.1 & -0.2 & -1.5 & -1.6 \\
\hline Bump & 3.6 & 9.7 & 8.5 & 6.4 & 10.6 & 10.4 \\
\hline Int & 15.3 & 7.5 & 2.6 & 2.6 & 7.6 & 8.8 \\
\hline
\end{tabular}

FreE the total energy of binding protein and related structure, Cntc the contact energy of interacting compounds (the related structure with protein), Hbnd the energy of hydrogen interactions, Bump the energy of steric clashes between protein and build-in structure, Int the energy of steric clashes between the atoms of build-in structure 
Fig. 1 MD for 2a-EGFR (a) and 2a-VEGFR2 (b) complexes
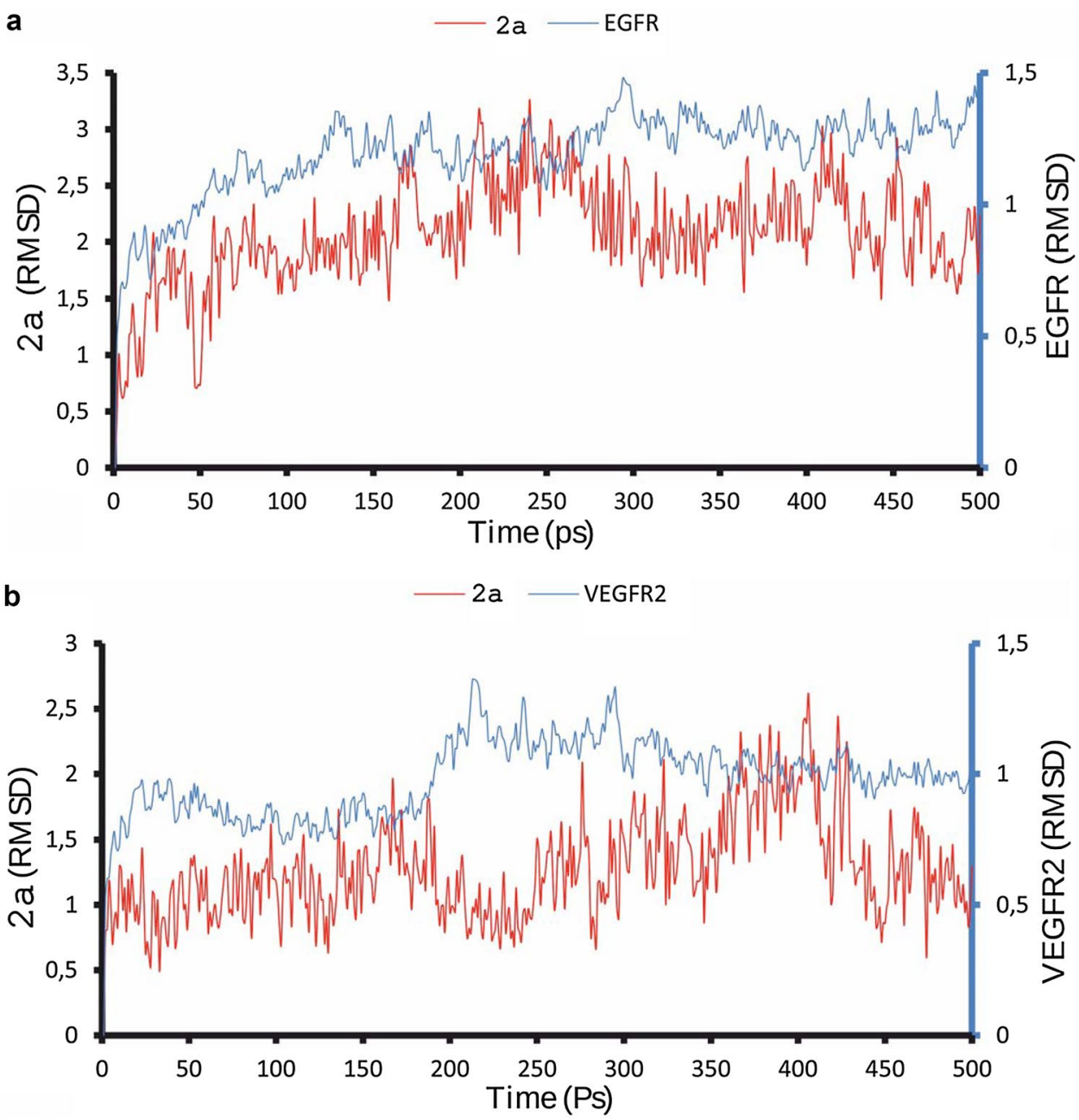

\section{Biological assays}

The discovery of any chemical with targeted action requires the investigation of its impact on the elements of protein kinase signaling cascades. The important element of functioning of cell membrane as the universal receptor, signaltransforming and regulatory system of the cell is the structural and functional state of its lipid matrix. Therefore, the determination of the drug's impact on cell membrane lipid matrix could be useful for complete understanding the mechanisms of action of that.
Since the main structure-forming component of plasma membrane is non-polar phospholipid phosphatidylcholine (PC, 39-78\% of the total lipid content), the membrane PCpool is the most likely targeted by the agent contacting with the cell. In addition, the lack of uncompensated electrostatic charges on the surface of the PC planar structures allows to determine the non-electrostatic component in the general mechanism of agent interaction with lipid bilayer.

The impact of 2a...2e on G and C of PC BLM was similar: both parameters increased in concentrationdependent manner (Table 4, Fig. 2), which could indicate
Table 4 The specific conductance and electric capacity of non-modified PC $\operatorname{BLM}\left(\mathrm{G}_{0}\right.$ and $\mathrm{C}_{0}$ respectively) and those modified with 2a...e $\left(\mathrm{G}_{\max }\right.$ and $\mathrm{C}_{\max }$ respectively) applied in the highest concentration $\left(10^{-5} \mathrm{M}\right.$ admixture), $\mathrm{M} \pm \mathrm{m}$

\begin{tabular}{lcccc}
\hline Compound & $\mathrm{G}_{0}, \mathrm{nS} / \mathrm{cm}^{2}$ & ${ }^{*} \mathrm{G}_{\max }, \mathrm{nS} / \mathrm{cm}^{2}$ & $\mathrm{C}_{0}, \mu \mathrm{F} / \mathrm{cm}^{2}$ & ${ }^{*} \mathrm{C}_{\max }, \mu \mathrm{F} / \mathrm{cm}^{2}$ \\
\hline $2 \mathrm{a}$ & $187.6 \pm 5.4$ & $227.0 \pm 7.56$ & $0.59 \pm 0.02$ & $0.68 \pm 0.02$ \\
2b & $138.1 \pm 14.38$ & $190.58 \pm 8.27$ & $0.63 \pm 0.05$ & $0.81 \pm 0.03$ \\
2c & $184.6 \pm 17.2$ & $252.91 \pm 6.83$ & $0.63 \pm 0.05$ & $0.79 \pm 0.02$ \\
$2 \mathrm{~d}$ & $156.57 \pm 13.73$ & $211.47 \pm 9.65$ & $0.56 \pm 0.06$ & $0.72 \pm 0.03$ \\
$\mathrm{2e}$ & $114.53 \pm 14.58$ & $162.63 \pm 10.31$ & $0.66 \pm 0.06$ & $0.89 \pm 0.02$ \\
\hline
\end{tabular}

* $\mathrm{p}<0.05$ compared to non-modified PC BLM 
Fig. 2 The relative changes in electric capacity (a) and specific conductance (b) of PC BLM after its modification by 4-amino-3-chloro- $1 \mathrm{H}$-pyrrole2,5-diones 2a...e applied in concentrations $10^{-9}-10^{-5} \mathrm{M}$. $1-\mathrm{p}<0.05$ compared to $10^{-9}$ $\mathrm{M}$ concentration, 2- $\mathrm{p}<0.05$ compared to $10^{-8} \mathrm{M}$ concentration, $3-\mathrm{p}<0.05$ compared to $10^{-7} \mathrm{M}$ concentration, $4-\mathrm{p}<0.05$ compared to $\mathbf{2 a}$ applied at the same concentration
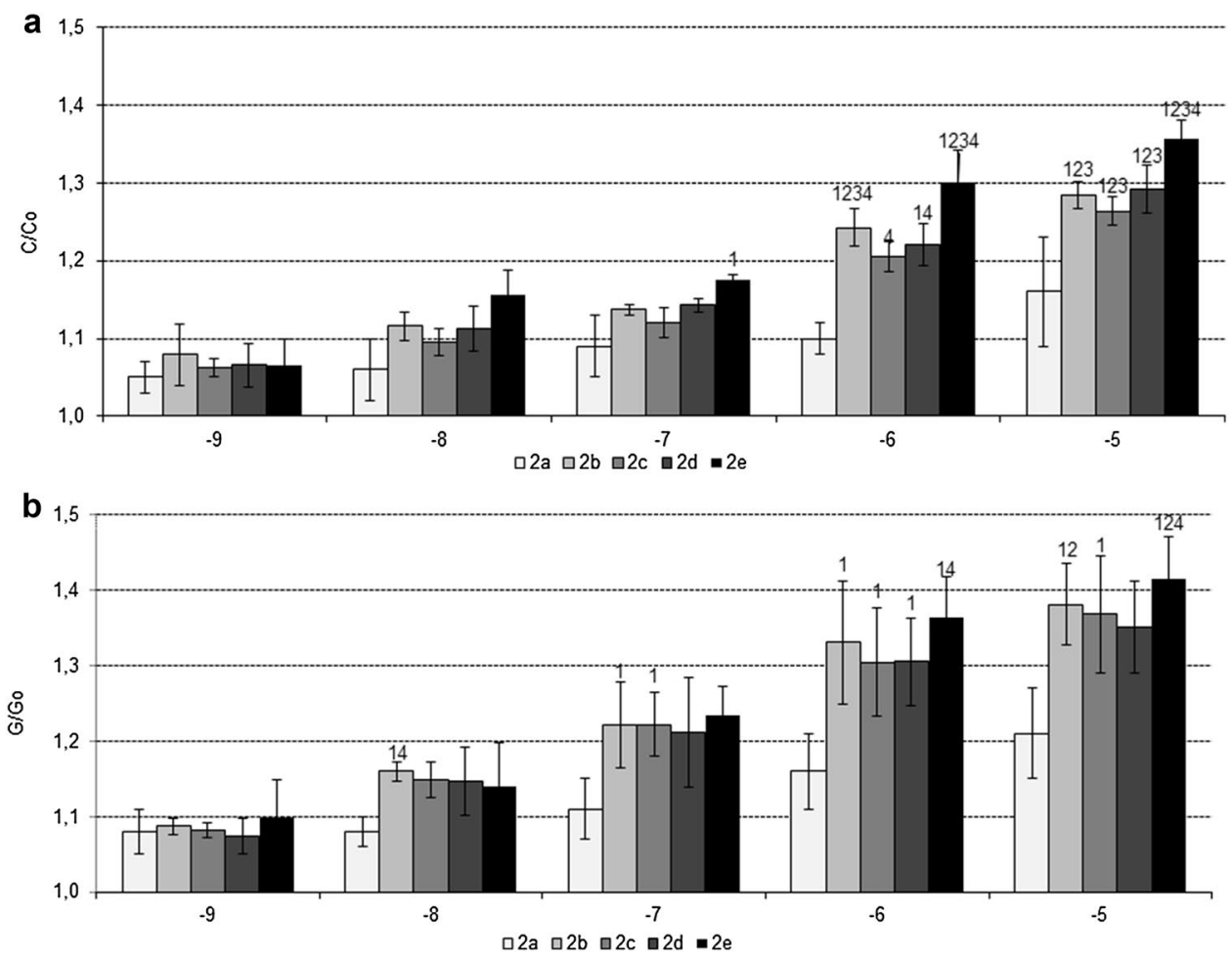

the intercalation of the molecules into the membrane. The consequence of the last might be decrease of the thickness of membrane hydrophobic region, which could indicate some disorganization of PCs in lipid bilayer. As all the tested compounds have aromatic groups, we suppose that their impact on the membrane lipid structure could be like cholesterol one. Indeed, $\mathrm{G}$ and $\mathrm{C}$ of erythrocyte membranes were increased after excessive accumulation of cholesterol in those (Kurilovich et al. 2009).

When comparing the effects of various 4-amino-3chloro- $1 H$-pyrrole-2,5-diones $\mathbf{2 a}$...e, the most intense changes in $\mathrm{G}$ and, especially, in $\mathrm{C}$ were caused by $\mathbf{2 e}$ (Fig. 2). This substance is characterized by increased mobility of side aromatic groups due to $-\mathrm{CH}_{2}-$ linkers between side groups and a pyrrole core of a molecule. Presumably, such mobility causes a more pronounced destabilizing effect of $\mathbf{2 e}$ on the membrane fatty acid matrix. It should be noted that such defects are non-destructive and rather like local low-intensity perturbations in the structure of lipid bilayer.

Tested compounds are not completely nonpolar but contain electronegative atoms/atomic groups. So, in order to detect the electrostatic interacting factor in the mechanism of their interaction with the membrane, their impact on the electrical characteristics of BLM constructed with different phospholipids were investigated. Asolectin (AS) membranes were used, their phospholipid composition was as follows: phosphatidylcholine:phosphatidylethanolamine:phosphatid ylinositol $=1: 1: 1$.
The general effects of 2a...2e on AS BLM G and C were similar to those on PC BLM ones, although the intensity of the effects differed considerably depending on the type of side group.

In contrast to the changes of PC BLM electrical characteristics, AS BLM G and C curves were sigmoid with saturation under 2 a...2e concentrations $10^{-7}-10^{-6} \mathrm{M}$ and oppression at the concentration $10^{-5} \mathrm{M}$ (Table 5). This could suggest the existence of some inhibitory factor in the mechanism of interaction of these compounds with lipid bilayer. We assume that non-compensated negative charge of anionic AS phospholipids could be this one, creating an additional surface electrostatic barrier against 2a...2e intercalation into the lipid bilayer (Nesterenko and Ermakov 2012).

When comparing the effects of various 4-amino-3-chloro$1 H$-pyrrole-2,5-diones $\mathbf{2 a}$...e, the most striking changes in electrical indices were caused by compound $\mathbf{2 e}$, as in case of PC BLM (Fig. 3). The reason is likely to be the same as in case of that interaction with PC BLM. However, despite the changes of PC and AS BLM G were similar, it should be noted that AS BLM C change was less than that of PC BLM. The reason might be the less number of $2 \mathbf{e}$ intercalated into AS BLM due to additional non-compensated negative charge on AS BLM surface compared to PC BLM one.

The effects of $2 \mathbf{a} \ldots \mathbf{d}$ on AS BLM also differed by the intensity. The structures of $\mathbf{2 b}$ and $\mathbf{2 c}$ are most similarthe only difference is the type of halogen atom in the 4 th position of the phenyl group ( $\mathrm{F}$ and $\mathrm{Cl}$, respectively). The changes both of AS BLM G and C after the impact of $\mathbf{2 b}$ and 
Table 5 The specific conductance and electric capacity of non-modified AS $\operatorname{BLM}\left(\mathrm{G}_{0}\right.$ and $\mathrm{C}_{0}$ respectively) and those modified with $2 a$...e applied in concentration caused the maximum effect ( $\mathrm{G}$ and $\mathrm{C}$ respectively), $\mathrm{M} \pm \mathrm{m}$

\begin{tabular}{lclll}
\hline Compound & $\mathrm{G}_{0}, \mathrm{nS} / \mathrm{cm}^{2}$ & ${ }^{*} \mathrm{G}, \mathrm{nS} / \mathrm{cm}^{2}$ & $\mathrm{C}_{0}, \mu \mathrm{F} / \mathrm{cm}^{2}$ & $\mathrm{C}, \mu \mathrm{F} / \mathrm{cm}^{2}$ \\
\hline $2 \mathrm{a}$ & $141.3 \pm 4.2$ & $193.58 \pm 7.56^{\mathrm{a}}$ & $0.67 \pm 0.06$ & $0.86 \pm 0.03^{\mathrm{a}^{*}}$ \\
$2 \mathrm{~b}$ & $157.3 \pm 9.72$ & $210.78 \pm 11.37^{\mathrm{b}}$ & $0.67 \pm 0.02$ & $0.81 \pm 0.03^{\mathrm{a}^{*}}$ \\
$2 \mathrm{c}$ & $169.8 \pm 11.1$ & $203.55 \pm 8.41^{\mathrm{b}}$ & $0.64 \pm 0.03$ & $0.68 \pm 0.03^{\mathrm{a}}$ \\
$2 \mathrm{~d}$ & $172.39 \pm 10.57$ & $210.32 \pm 5.87^{\mathrm{d}}$ & $0.61 \pm 0.05$ & $0.71 \pm 0.03^{\mathrm{c}}$ \\
$2 \mathrm{e}$ & $132.27 \pm 7.81$ & $185.44 \pm 8.37^{\mathrm{b}}$ & $0.59 \pm 0.03$ & $0.71 \pm 0.02^{\mathrm{b}^{*}}$ \\
\hline
\end{tabular}

Concentration of $2 \mathrm{a} . . .2 \mathrm{e}:{ }^{\mathrm{a}} 10^{-5} \mathrm{M},{ }^{\mathrm{b}} 10^{-6} \mathrm{M},{ }^{\mathrm{c}} 10^{-7} \mathrm{M},{ }^{\mathrm{d}} 10^{-8} \mathrm{M}, * \mathrm{p}<0.05$ compared to non-modified AS BLM

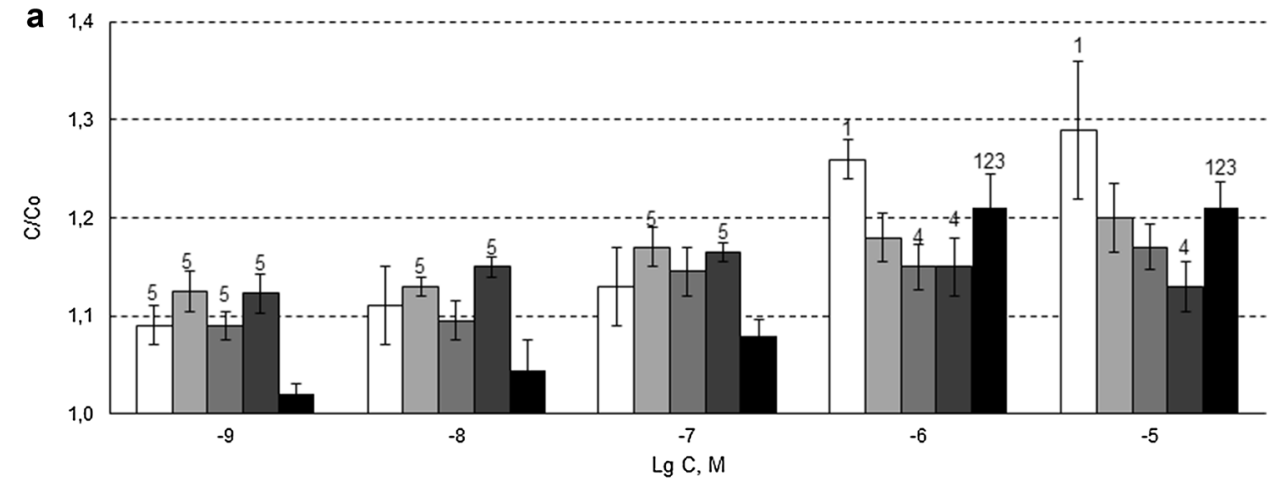

$\square 2 a \square 2 b \square 2 c-2 d=2 e$

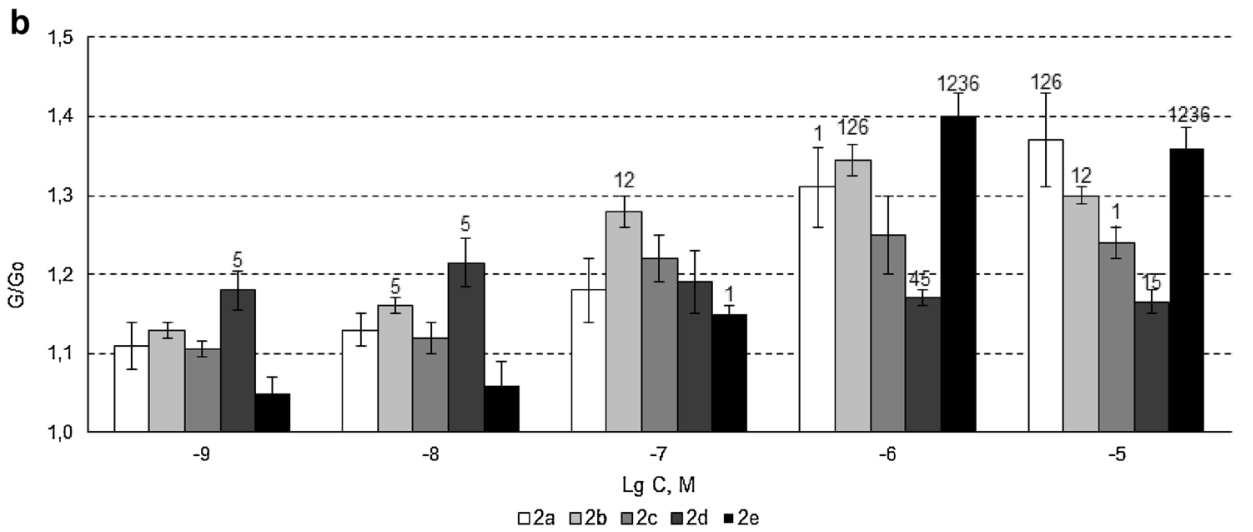

Fig. 3 The relative changes of electric capacity (a) and specific conductance (b) of AS BLM after its modification by 4-amino-3-chloro- $1 \mathrm{H}$-pyrrole2,5-diones 2a...e applied in concentrations $10^{-9}-10^{-5} \mathrm{M}$. $1-\mathrm{p}<0.05$ compared to $10^{-9}$ $\mathrm{M}$ concentration, $2-\mathrm{p}<0.05$ compared to $10^{-8} \mathrm{M}$ concentration, $3-\mathrm{p}<0.05$ compared to $10^{-7} \mathrm{M}$ concentration, $4-\mathrm{p}<0.05$ compared to $\mathbf{2 a}$ applied at the same concentration, $5-\mathrm{p}<0.05$ compared to 2e applied at the same concentration, $6-\mathrm{p}<0.05$ compared to $\mathbf{2 d}$ applied at the same concentration $\mathbf{2 c}$ are practically the same, but the effects of $\mathbf{2 b}$ are more intense compared to $\mathbf{2 c}$ when applied in all investigated concentrations. This could be explained by greater electronegativity of the $\mathrm{F}$ atom compared to $\mathrm{Cl}$ one and, consequently, by more intensive intercalation of $\mathbf{2 b}$ into the BLM. The similar effects were demonstrated in (Bychko et al. 2014): if the molecules have different electronegative groups in the same position, the more electronegative the group the stronger the effect. In theory, compounds with positively charged groups should interact with AS BLM more intensively (Garcia-Celma et al. 2007). However, highly electronegative groups $(-\mathrm{F},-\mathrm{Cl})$ could probably interact with positively charged groups $\left(\mathrm{N}\left(\mathrm{CH}_{3}\right)^{+}, \mathrm{NH}_{3}{ }^{+}\right)$of phospholipids forming AS BLM, as well as with $\mathrm{OH}$-groups of inositol, herewith the more electronegative the group the more intensive the interaction. Compound $\mathbf{2 d}$, having $C F_{3}$-group (the most electronegative) in the 3rd position of phenyl, exhibits the strongest effects at low concentrations. Saturation of the membrane surface with $2 \mathbf{d}$ might occur already at $10^{-8}-10^{-7}$ $\mathrm{M}$ concentration, probably due to the large electronegativity and size of abovementioned group. Therefore, further increase of $\mathbf{2 d}$ concentration might cause BLM G and C diminish.

Thus, the character of membranotropic activity of the chemicals is modified significantly in anionic phospholipid pool and directly depends on the structure of their side groups. The general analysis of the obtained results suggests the following mechanism of the interaction of 4-amino-3-chloro- $1 \mathrm{H}$ pyrrole-2,5-diones 2a...e with membrane lipid matrix: the chemicals could absorb on the lipid bilayer surface and involve into electrostatic interactions with polar groups of phospholipid heads. Wherein intensity of the interaction depends on 
the type of side groups: the more electronegative and mobile the group (existence of $-\mathrm{CH}_{2}$ - linkers between side group and pyrrole core), the more intensive the interaction and more pronounced the membranotropic effect. Presumably, the impact of 2a...e on lipid bilayer is the most intensive in clusters of cationic and anionic lipids. Apparently, partial intercalation of the chemicals into hydrophobic zone of lipid bilayer occurs in these clusters, leading to lipid packing destabilization. In general, it could cause the structural disturbances in lipid bilayer, a decrease of its thickness and an increase of its permeability for charged particles. However, such defects are likely to be local low-intensive perturbations in lipid bilayer structure and do not affect the integrity of the membrane.

Obviously, that analysis of the ability of any newly synthesized targeted compound to bind its molecular target and to compete successfully with natural ligands is the first step in assessment of its therapeutic potential. The second one is seeking the ways to optimize the initial structure for: (1) improving the binding its target, (2) improving the ability to enter into the cell if the target is situated inside it, and (3) decrease the possible toxicity for the organism. Our results demonstrated the ability of 2a...2e not only to bind with ATP-binding site of EGFR and VEGFR2 but to do it more effectively compared to ANP. Also we can see, that 2a...2e cause the maximum effect on lipid membrane in different concentrations. Moreover, every compound from this set has special concentrationdependent curve of effect. This allows not only to choose the structure optimal for specific therapeutic task, but to propose optimal concentration this compound might be applied in. Furthermore, we demonstrated that every investigated compound did not cause the changes in $\mathrm{C}$ and $\mathrm{G}$ of model membranes which could be interpreted as destructive ones. Taking into account the similar effects of $\mathbf{2 a . . . 2 e ~ o n ~ m o d e l ~ m e m b r a n e s ~}$ and low toxicity of 2a (Kuznietsova et al. 2013, 2015) we might suggest low toxicity of all the investigated compounds. At the same time, observed changes let us to conclude the ability of 2a...2e to intercalate into the membrane and therefore probably to react with intramembrane or submembrane domains of the receptors, such as those with protein kinase activity. Notably, that lipophilic efficiency is an important criterion of small molecule protein kinase inhibitors, as well as considerably low molecular weight (Roskoski 2019). Thus, the reported compounds could be non-toxic agents which are able to interact with cell membrane and to inhibit growth factor receptors like EGFR and VEGFR2 and therefore warrant further optimization as novel members in cancer treatment protocols.

\section{Conclusions}

1. The investigated 4-amino-3-chloro- $1 H$-pyrrole-2,5diones demonstrated the potential ability to form complexes with EGFR and VEGFR2, which are more stable compared to those with ANP (the structural analogue of ATP).

2. The interaction of 4-amino-3-chloro-1H-pyrrole-2,5diones with BLM causes the certain disturbance in BLM structure leading to an increase of its specific conductance and electric capacity.

3. The structure of 4-amino-3-chloro-1H-pyrrole-2,5-diones' side groups has little effect on the intensity of their impact on neutral planar lipid structures, but plays a key role in contact of those with the membranes of mixed composition.

4. Obtained data allow to suggest that proposed chemicals can interact with the surface of lipid bilayer, do likely intercalate into the membrane and form stable complexes with EGFR and VEGFR2 inhibiting their activity.

Summing up, the reported compounds could be nontoxic agents which are able to interact with cell membrane and to inhibit EGFR and VEGFR2. Therefore, these chemicals might deserve to be considered and investigated as potential anticancer therapeutics.

Acknowledgements The research was carried out in the frame of the Fundamental research grants of Ministry of Education and Science of Ukraine No. 0118 U000244 and No. 19BP07-03.

\section{Compliance with ethical standards}

Conflict of interest The authors declare that there is no conflict of interest regarding the publication of this paper.

\section{References}

Arakelyan VB, Torosyan AL, Ghazaryan RK (2014) Cyclic currentvoltage characteristics of a bilayer lipid membrane in the presence of porphyrin. Proc YSU Phys Mathes 2:60-63

Bond SD, Leimkuhler BJ, Laird BB (1999) The Nosé-Poincaré method for constant temperature molecular dynamics. J Comput Phys 151:114-134

Broekman F, Giovannetti E, Peters GJ (2011) Tyrosine kinase inhibitors: multi-targeted or single-targeted? World J Clin Oncol 2:80-93

Bychko A, Artemenko A, Byelinska I, Gurnyak O, Rybalchenko V (2014) Membranotropic and cellular effects of maleimide derivatives as potential antitumor compounds. Visnyk of the Lviv University. Ser Biol 68:79-90

Di Maio M, Basch E, Bryce J, Perrone F (2016) Patient-reported outcomes in the evaluation of toxicity of anticancer treatments. Nat Rev Clin Oncol 13:319-325 
Dubinina GG, Golovach SM, Kozlovsky VO, Tolmachov AO, Volovenko YuM (2007) Antiproliferative action of the new derivatives of 1-(4-R-benzyl)-3-R1-4-(R2-phenylamino)-1Hpyrrol-2,5-dione. Zh Org Farm Khim 5:39-49

Elez E, Macarulla T, Tabernero J (2008) Handling side-effects of targeted therapies: safety of targeted therapies in solid tumours. Ann Oncol 19:vii146-vii152

Garcia-Celma JJ, Hatahet L, Kunz W, Fendler K (2007) Specific anion and cation binding to lipid membranes investigated on a solid supported membrane. Langmuir 23:10074-10080

Garmanchuk LV, Denis EO, Nikulina VV, Dzhus OI, Skachkova OV, Ribalchenko VK, Ostapchenko LI (2013a) MI1-derivative of maleimide inhibits progression of tumor cells of epithelial origin. Biopolym Cell 29:70-74

Garmanchuk LV, Linchak OV, Denis EO, Nikulina VV, Dzhus OI, Khranovskaya NN, Nikolaenko TV, Babuta EN, Rybalchenko VK (2013b) Potential cytostatic effect of the maleimide derivative 1-(4-Cl-benzyl)-3-Cl-4-(CF3-phenylamino)-1H-pyrrol-2,5-dione. Eksp Klin Farmakol 76:39-42

Gerber DE (2008) Targeted therapies: a new generation of cancer treatments. Am Fam Physician 77:311-319

Jorgensen WL, Chandrasekhar J, Madura JD, Impey RW, Klein ML (1983) Comparison of simple potential functions for simulating liquid water. J Chem Phys 79:926-935

Koper I, Stefan M, Schiller SM, Giess F, Naumann R, Knoll W (2006) Functional tethered bimolecular lipid membranes (tBLMs). In: Leitmannova Liu A (ed) Advances in planar lipid bilayers and liposomes. Elsevier, Amsterdam, pp 37-53

Kroschinsky F, Stölzel F, von Bonin S, Beutel G, Kochanek M, Kiehl $\mathrm{M}$, Schellongowski P, Intensive Care in Hematological and Oncological Patients (iCHOP) Collaborative Group (2017) New drugs, new toxicities: severe side effects of modern targeted and immunotherapy of cancer and their management. Crit Care 14:1-11

Kurilovich SA, Kruchinina MV, Generalov VM, Bakirov TS, Rikhter VA, Semenov DV (2009) Electrical parameters and structure of membranes of erythrocytes at diffuse liver diseases. Russ J Gastroenterol Hepatol Coloproctol 19:30-36

Kuznietsova HM, Lynchak OV, Danylov MO, Kotlyar IP, Rybalchenko VK (2013) Effects of dihydropyrrol and maleimide derivatives on state of liver and colon in normal rats and in setting of colorectal carcinogenesis. Ukr Biochem J 85:62-72

Kuznietsova HM, Luzhenetska VK, Kotliar IP, Rybalchenko VK (2015) Effects of 5-Amyno-4-(1,3-benzothyazol-2-yn)-1-(3methoxyphenyl)-1,2-dihydro-3H-pyrrol-3-one intake on digestive system in a rat model of colon cancer. Sci World J. https://doi. org/10.1155/2015/376576

Kuznietsova HM, Yena MS, Kotliar IP, Rybalchenko VK (2016) Antiinflammatory effects of protein kinase inhibitor pyrrol derivate. Sci World J. https://doi.org/10.1155/2016/2145753
Liu W, Beck J, Schmidt LC, Roolf C, Pews-Davtyan A, Rütgen BC, Hammer S, Willenbrock S, Sekora A, Rolfs A, Beller M, Brenig B, Nolte I, Junghanss C, Schütz E, Murua Escobar H (2016) Characterization of the novel indolylmaleimides' PDA-66 and PDA377 effect on canine lymphoma cells. Oncotarget 7:35379-35389

McMartin C, Bohacek RS (1997) QXP: powerful, rapid computer algorithms for structure-based drug design. J Comput Aided Mol Des 11:333-344

Nesterenko AM, Ermakov YuA (2012) Molecular-dynamic simulation of phospholipid bilayers: ion distribution at the surface of neutral and charged bilayer in the liquid crystalline state. Biochem Moscow Suppl Ser A 6:320-328

Ostrovska GV, Nizheradze KA, Dubinina GG, Rybalchenko VK (2007) Cytostatic action of maleimide derivatives on HEK-293 cell line. In: II Ukrainian cell biology society meeting (Kyiv), p 126

Pajak B, Orzechowska S, Gajkowska B, Orzechowski A (2008) Bisindolylmaleimides in anti-cancer therapy-more than PKC inhibitors. Adv Med Sci 53:21-31

Pestalozzi BC, Knuth A (2004) New antibodies in cancer treatment. Praxis 93:1589-1592

Relles MH (1973) Dichloromaleimide Chemistry. II. A thionyl chloride-pyridine method for the conversion of maleimides to dichloromaleimides. J Org Chem 37:3630-3637

Roskoski R (2019) Properties of FDA-approved small molecule protein kinase inhibitors. Pharmacol Res 144:19-50

Stewart BW, Wild CP (2014) World cancer report. International Agency for Research on Cancer, Lyon

Sturgeon JB, Laird BB (2000) Symplectic algorithm for constantpressure molecular-dynamics using a Nose-Poincare thermostat. J Chem Phys 112:3474-3482

van Eis MJ, Evenou J, Schuler W, Zenke G, Vangrevelinghe E, Wagner J, von Matt P (2017) Indolyl-naphthyl-maleimides as potent and selective inhibitors of protein kinase $\mathrm{C}-\alpha / \beta$. Bioorg Med Chem Lett 27:781-786

Warren GL, Andrews CW, Capelli AM, Clarke B, LaLonde J, Lambert MH, Lindvall M, Nevins N, Semus SF, Senger S, Tedesco G, Wall ID, Woolven JM, Peishoff CE, Head MS (2006) A critical assessment of docking programs and scoring functions. J Med Chem 49:5912-5931

Publisher's Note Springer Nature remains neutral with regard to jurisdictional claims in published maps and institutional affiliations. 